\title{
EFFECT OF HEAT TREATMENT ON MICROSTRUCTURE AND PROPERTIES OF Ti-22AI-25Nb ALLOY FABRICATED BY SELECTIVE LASER MELTING
}

\author{
Igor POLOZOV, Vadim SUFIIAROV, Artem KANTYUKOV, Anatoliy POPOVICH
}

\author{
Peter the Great St, Petersburg Polytechnic University, Russian Federation, polozov ia@spbstu.ru \\ https://doi.org/10.37904/metal.2019.933
}

\begin{abstract}
Ti-22Al-25Nb orthorhombic alloy is considered to be an advanced intermetallic alloy for high-temperature applications. In this paper, the effects of Hot Isostatic Pressure (HIP), homogenizing annealing and aging in different phase regions on microstructure and microhardness of the Ti-22Al-25Nb alloy obtained from elemental powders by Selective Laser Melting (SLM) were studied. HIP allowed to reduce the residual porosity in the samples, however high-temperature annealing was needed to dissolve $\mathrm{Nb}$ particles and obtain a homogeneous microstructure. Differential Scanning Calorimetry was used to determine phase transition temperatures in the fabricated alloy and allowed to choose appropriate aging temperatures. Aging of the alloy resulted in the formation of intermetallic $\mathrm{Ti}_{2} \mathrm{AINb}$ and $\mathrm{Ti}_{3} \mathrm{Al}$ phase depending on the temperature.
\end{abstract}

Keywords: Additive manufacturing, Ti-22Al-25Nb, heat treatment, microstructure, intermetallic

\section{INTRODUCTION}

Intermetallic alloys based on $\mathrm{TiAl}, \mathrm{Ti}_{3} \mathrm{Al}, \mathrm{Ti}_{2} \mathrm{AINb}$ titanium aluminides present a material class with high yield strength, low-cycle fatigue, creep resistance and a high working temperature up to $650^{\circ} \mathrm{C}$ [1]. Intermetallic titanium alloys are considered to be excellent candidates for replacing nickel-based heat-resistant materials in aerospace, automotive and energy industries due to their combination of physical and mechanical properties [2]. $\mathrm{Ti}_{2} \mathrm{AINb}$-based alloys with orthorhombic crystal structure have enhanced ductility and corrosion resistance compared to the alloys based on other aluminides and are considered as advanced alloys for manufacturing of gas-turbine engine parts [3]. Intermetallic titanium alloys are of particular interest for Additive manufacturing (AM) due to their hard machinability and high cost of production by conventional methods.

While in the previous work [4] it was shown that Ti-22Al-25Nb alloy can be synthesized from elemental powder mixtures by Selective Laser Melting technology, it is still important to investigate the effect of heat treatment at different conditions on microstructure and properties of the alloy to achieve optimal performance of the material.

In the recent years, there have been studies devoted to heat treatment of $\mathrm{Ti}_{2} \mathrm{AINb}$-based alloys obtained by various techniques, e.g. spark plasma sintering [5], forging [6], hot pressing sintering [7]. They showed that by varying annealing and aging temperature and cooling rates it is possible to influence a morphology, quantity, and type of intermetallic phases as well as grains size. At the same time, microstructures of the alloys obtained by AM are generally significantly different from conventionally obtained alloys. Thus, it is needed to investigate effects of different heat treatment conditions on microstructure of the Additive Manufactured intermetallic alloy.

In this paper, we study the effect of Hot Isostatic Pressing (HIP), homogenizing annealing, and aging in the range of $700-1100{ }^{\circ} \mathrm{C}$ on microstructure, phase composition, and microhardness of the Ti-22Al-25Nb alloy manufactured by SLM.

\section{MATERIALS AND METHODS}

Spherical elemental powders of CP Ti Grade 2, Al (purity $99.9 \%$ ), Nb (purity $99.7 \%$ ) were used as the initial powders for preparing a mix of elemental powders in the composition of Ti-22Al-25Nb (at\%). The elemental 
powder mixture had the following particle size distribution: $d_{10}=17.9 \mu \mathrm{m}, d_{50}=34.0 \mu \mathrm{m}, d_{90}=60.2 \mu \mathrm{m}$.

The SLM process was carried out using SLM Solutions SLM $280 \mathrm{HL}$ machine. The samples with the size of $10 \times 10 \times 10 \mathrm{~mm}^{3}$ were manufactured at $55.6 \mathrm{~J} / \mathrm{mm}^{3}$ volume energy density with the previously optimized parameters allowing to obtain samples with a relative density $99.5 \%$.

The phase composition was analyzed with a Bruker D8 Advance X-ray diffraction (XRD) meter using Cu-Ka $(\lambda=0.15418 \mathrm{~nm})$ irradiation.

Buehler VH1150 testing machine with $10 \mathrm{~s}$ dwelling time and $500 \mathrm{~g}$ load was used to evaluate the microhardness of the produced samples.

TESCAN Mira 3 LMU scanning electron microscope (SEM) with secondary electrons (SE) and backscattered electrons (BSE) was utilized for the microstructural characterization of the samples.

Hot isostatic pressuring (HIP) of the samples was carried out at $1050^{\circ} \mathrm{C}$ temperature and $100 \mathrm{MPa}$ pressure for 3 hours using argon gas. Heat treatment of the samples consisted of annealing in vacuum at $1350^{\circ} \mathrm{C}$ for 2 $\mathrm{h}$ followed by approximately $4-6^{\circ} \mathrm{C} / \mathrm{s}$ cooling and aging in vacuum at $700,800,900,1000$, and $1100{ }^{\circ} \mathrm{C}$ for 24 $\mathrm{h}$ followed by furnace cooling.

Differential Scanning Calorimetry (DSC) was carried out using SETSYS Evolution analyzer with the heating rate of $5^{\circ} \mathrm{C} / \mathrm{min}$ and maximum temperature of $1400^{\circ} \mathrm{C}$ in an argon atmosphere.

\section{RESULTS AND DISCUSSION}

To determine phase transformation temperatures in the synthesized alloy, a thermal analysis of the sample produced at $55 \mathrm{~J} / \mathrm{mm}^{3}$ after homogenizing annealing at $1350^{\circ} \mathrm{C}$ was conducted by way of DSC. The DSCcurve is shown in Figure 1. There are two exothermal (at $860^{\circ} \mathrm{C}$ and $1069^{\circ} \mathrm{C}$ ) and two endothermal peaks (at $978{ }^{\circ} \mathrm{C}$ and $1238{ }^{\circ} \mathrm{C}$ ) found on the DSC-curve. The first DSC-peak at $860{ }^{\circ} \mathrm{C}$ corresponds to $\mathrm{O} \rightarrow \mathrm{B} 2$ transition. The B2 phase corresponds to the Ti-Al$\mathrm{Nb}$ solid solution with the ordered body centered cubic lattice, that is typical for titanium intermetallic alloy with high $\mathrm{Nb}$ content. The O-phase corresponds to the $\mathrm{Ti}_{2} \mathrm{AINb}$ compound with the ordered orthorhombic lattice. The endothermal peak at $978^{\circ} \mathrm{C}$ corresponds to the formation of a2phase. The exothermal peak at $1069{ }^{\circ} \mathrm{C}$ corresponds to the dissolution of O-phase. The peak at $1238{ }^{\circ} \mathrm{C}$ corresponds to a2-phase dissolution and transition to a single-phase B2region. The DSC-curve peaks correspond to typical phase transitions for Ti-22Al-25Nb alloy. However, transition temperatures are shifted towards higher temperatures, which might be the result of the reduced $\mathrm{Al}$ content. Therefore, $\mathrm{Nb}$ content in the sample is relatively higher than in the powder mixture leading to increased

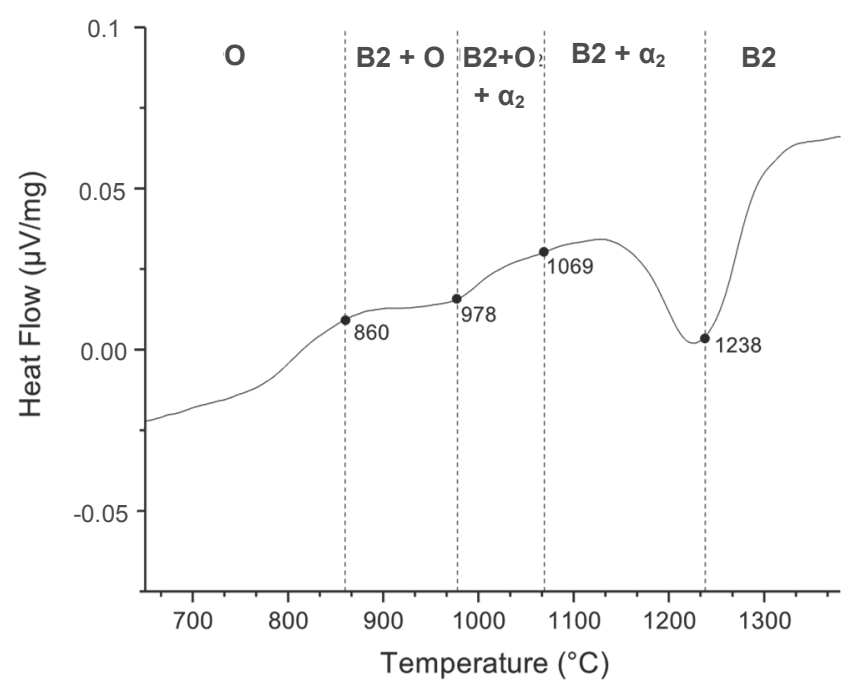

Figure 1 DSC-curve of the sample produced by SLM from Ti-22Al-25Nb elemental powder mixture temperature stability of B2-phase.

The samples obtained by SLM were HIPed at $1050^{\circ} \mathrm{C}, 100 \mathrm{MPa}$ for $3 \mathrm{~h}$. SEM-BSE-image of the microstructure and EBSD map of the sample after HIP are shown in Figure 2. HIP allowed to obtain almost fully-dense material by closing the residual pores. However, there are still separate undissolved $\mathrm{Nb}$ particles in the sample. Thus, the used HIP temperature was not high enough to promote full dissolution of $\mathrm{Nb}$ in the sample. However, 
HIP at $1050^{\circ} \mathrm{C}$ followed by slow cooling resulted in the formation of secondary phase precipitates. According to the XRD results (Figure 3), these precipitates are $\alpha_{2}$-phase ( $\left(\mathrm{Ti}_{3} \mathrm{Al}\right.$ ). The EBSD results (Figure $\mathbf{2} \mathbf{b}$ ) showed that the sample after HIP consists of equiaxed with different crystallographic orientations with a mean grain size of about $50 \mu \mathrm{m}$.
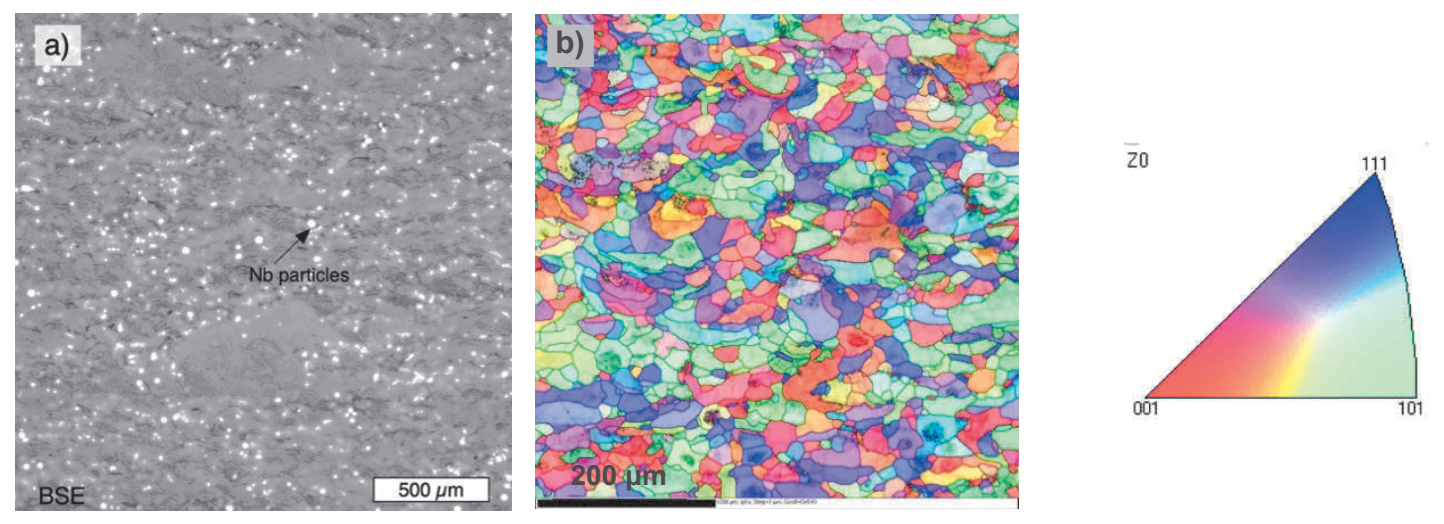

Figure 2 SEM-image of Ti-22Al-25Nb sample's microstructure after HIP (a) and inverse pole figure (IPF) map showing the grain distribution and orientation

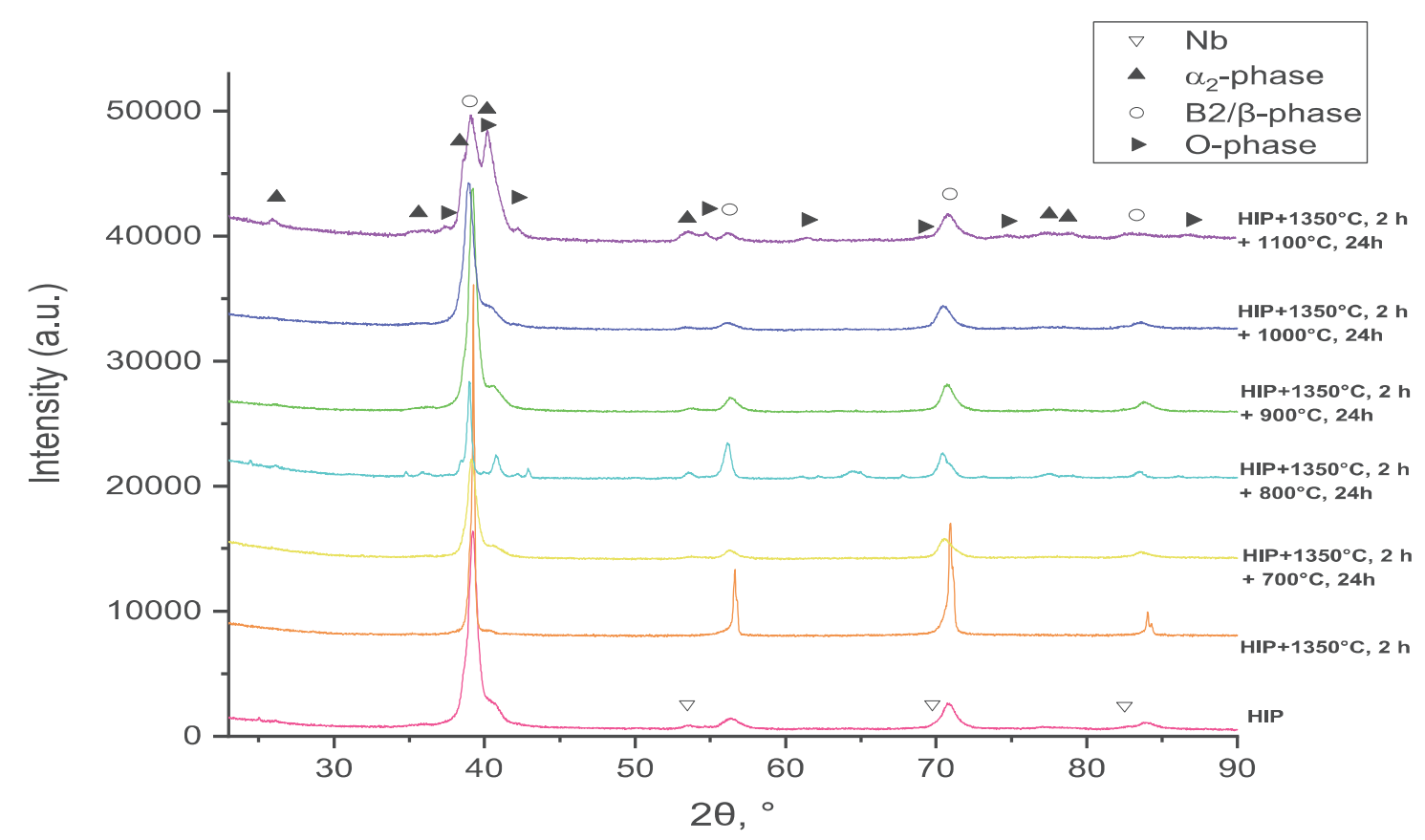

Figure 3 The XRD patterns of Ti-22Al-25Nb samples produced by SLM after HIP and various heat treatment

In order to dissolve $\mathrm{Nb}$ particles the HIPed samples were annealed in vacuum at $1350^{\circ} \mathrm{C}$ for $2 \mathrm{~h}$. Annealing at $1350^{\circ} \mathrm{C}$ resulted in diffusion and dissolution of $\mathrm{Nb}$ particles in the alloy. The XRD pattern of the annealed sample shows only the peaks corresponding to B2-phase (Figure 3). No secondary precipitates were found in the microstructure, which were the results of a relatively high cooling rate $\left(5-7{ }^{\circ} \mathrm{C} / \mathrm{s}\right)$ from the annealing temperature.

To increase the strength of the alloy the amount of intermetallic orthorhombic Ti2AlNb-phase must be increased. For that purpose, the samples after annealing were aged at $700,800,900,1000,1100{ }^{\circ} \mathrm{C}$ for $24 \mathrm{~h}$ in vacuum. Based on the DSC-results, these temperatures correspond to different phase regions of the 
obtained alloy. The microstructures of the samples aged at $700-900^{\circ} \mathrm{C}$ are shown in Figure 4. Aging at these temperatures resulted in precipitation of fine acicular O-phase of different width inside B2-grains. O-phase precipitates can also be found on the B2-grains borders. The EDX results showed that the composition of Ophase on the grain boundaries after aging at $700^{\circ} \mathrm{C}$ is the following (in at. \%): $\mathrm{Ti}-59.6, \mathrm{Al}-23.0 ; \mathrm{Nb}-17.4$.
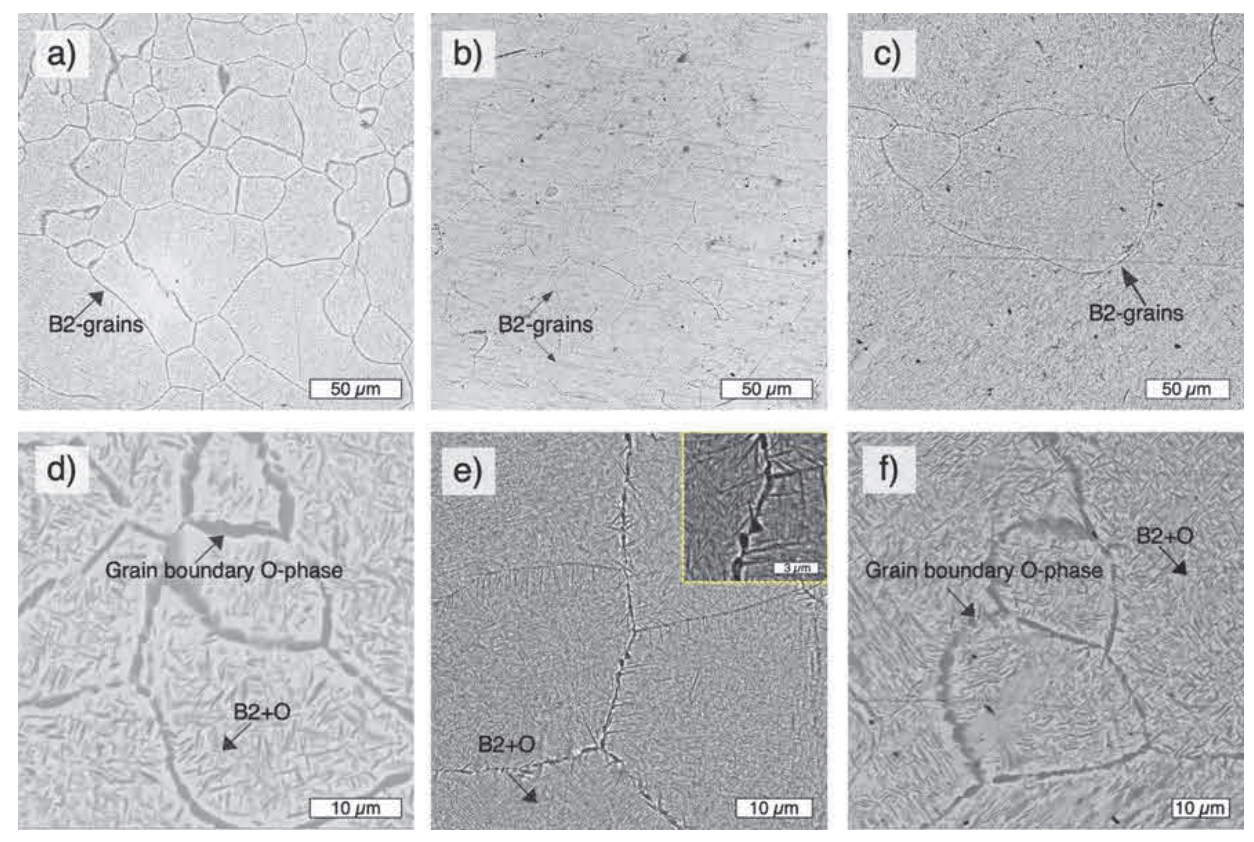

Figure 4 SEM-images of the Ti-22Al-25Nb samples after aging for $24 \mathrm{~h}$ at $700^{\circ} \mathrm{C}(\mathrm{a}, \mathrm{d}), 800^{\circ} \mathrm{C}(\mathrm{b}, \mathrm{e})$, and $900^{\circ} \mathrm{C}(\mathrm{c}, \mathrm{f})$

Aging at $700{ }^{\circ} \mathrm{C}$ resulted in the smallest volume fraction of O-phase, which is $34 \pm 3 \%$. Aging at $800{ }^{\circ} \mathrm{C}$ increased the O-phase volume fraction to $46.3 \%$ while aging at $900^{\circ} \mathrm{C}$ slightly decreased the O-phase fraction to $42 \pm 2 \%$. Aging at $800^{\circ} \mathrm{C}$ resulted to the smallest width of O-phase precipitates $(0.12 \pm 0.04 \mu \mathrm{m})$. Figure 5 shows the EBSD for the samples aged at $800{ }^{\circ} \mathrm{C}$. The sample has equiaxed grains with different crystallographic orientations. The grains size increased to about 400-500 $\mu \mathrm{m}$ as the result of annealing and aging treatments. Aging of the alloy in $\left(B 2+O+\alpha_{2}\right)$-phase region at $1000{ }^{\circ} \mathrm{C}$ results in the formation of fine $\alpha_{2-}$ $\mathrm{Ti}_{3} \mathrm{Al}$ precipitates inside B2-grains, while O-phase can only be found at B2-grain boundaries (Figures 6 a, c). Aging at $1100^{\circ} \mathrm{C}$ led to the precipitation of a high number of fine $\alpha_{2}-\mathrm{Ti}_{3} \mathrm{Al}$ precipitates with the width of $1-2 \mu \mathrm{m}$ inside B2-grains and the precipitation of O-phase (Figures $\mathbf{6} \mathbf{b}$, d). The higher amount of O-phase in case of aging at $1100^{\circ} \mathrm{C}$ compared to $1000^{\circ} \mathrm{C}$ can be attributed to the decomposition of $\alpha_{2}$-phase during slow cooling in (B2+O)-region.
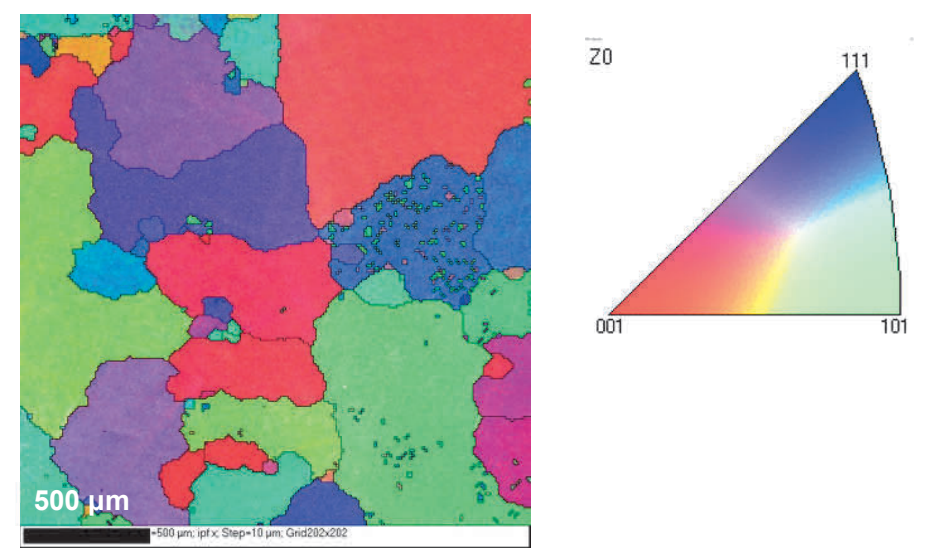

Figure 5 IPF map showing the grain distribution and orientation for the sample aged at $800^{\circ} \mathrm{C}$ 

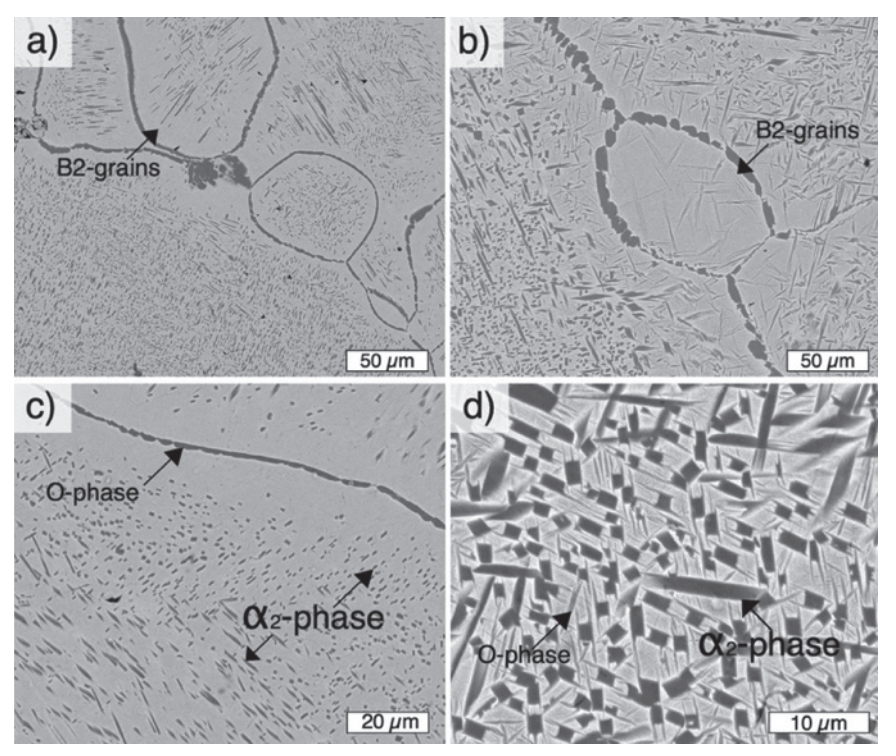

Figure 6 SEM-images of Ti-22Al-25Nb samples after aging for $24 \mathrm{~h}$ at $1000^{\circ} \mathrm{C}(\mathrm{a}, \mathrm{C})$, and $1100{ }^{\circ} \mathrm{C}(\mathrm{b}, \mathrm{d})$

The microhardness of the samples obtained by SLM at different conditions and after different heat-treatment is shown in Figure 7. Homogenizing annealing resulted in lower microhardness due to the formation of B2phase without any strengthening secondary phase precipitates. Subsequent aging increased the microhardn̄ss. The highest microhardness was achieved after aging at $800^{\circ} \mathrm{C}$ provided that the produced alloy featured the largest amount of O-phase precipitates with the smallest width.

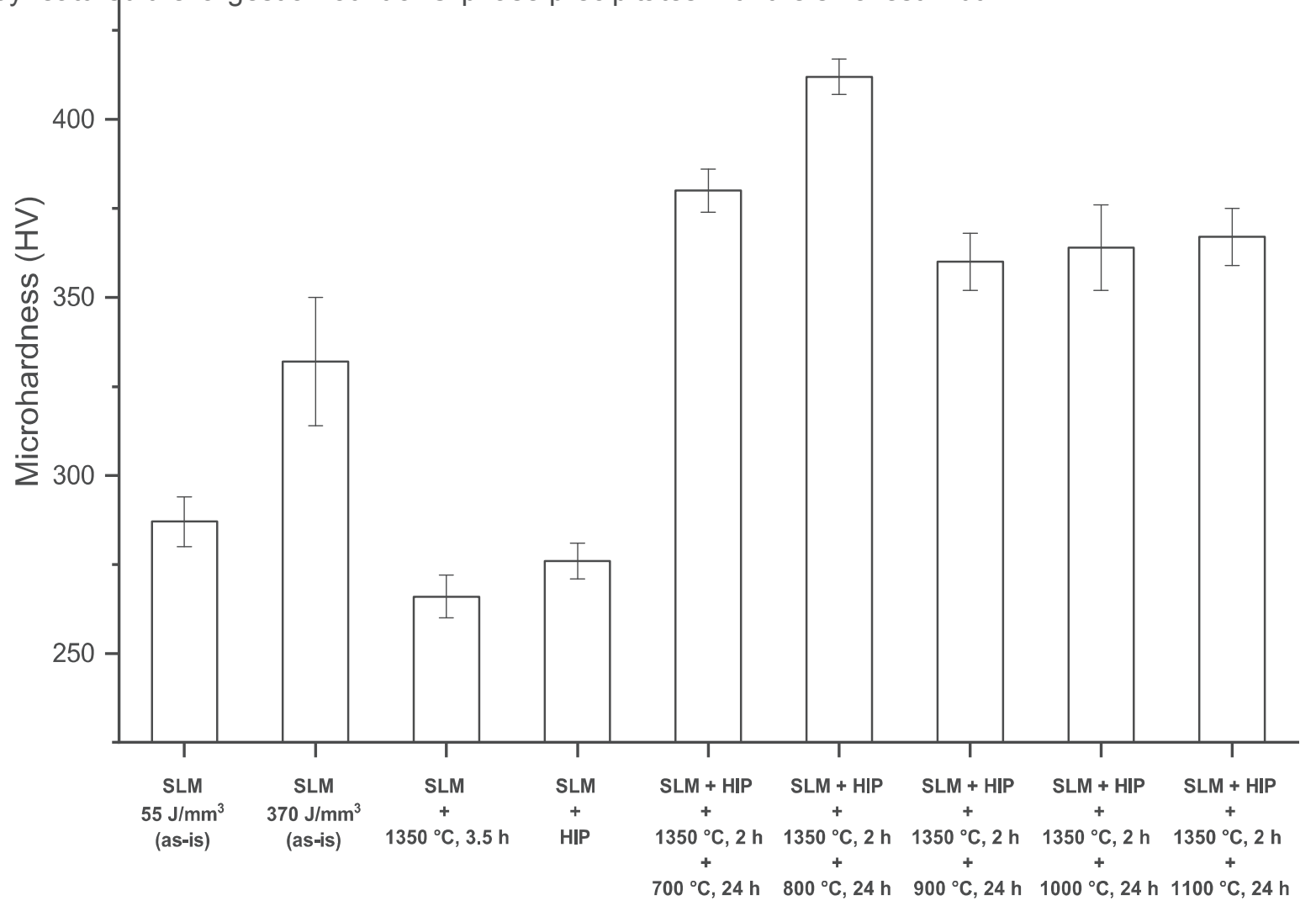

Figure 7 The microhardness of the samples obtained by SLM from Ti-22Al-25Nb elemental powder mixture at different conditions 


\section{CONCLUSIONS}

The paper demonstrates the results of study of HIP and heat treatment effects on microstructure and properties of the Ti-22Al-25Nb alloy obtained by SLM from elemental powders. It was shown that HIP at $1050^{\circ} \mathrm{C}$ resulted in fully-dense material, while $\mathrm{Nb}$ particles remained undissolved. a2-Ti3 $\mathrm{Al}$ precipitates formed around $\mathrm{Nb}$ particles. Annealing at $1350{ }^{\circ} \mathrm{C}$ for $2 \mathrm{~h}$ dissolved $\mathrm{Nb}$ particles in B2-solid solution. Aging temperature significantly affects the size and the number of secondary precipitates. The highest volume fraction of O-phase precipitates having the smallest size was obtained after aging at $800{ }^{\circ} \mathrm{C}$ in (B2+O)-phase region. Heat treatment conditions significantly affect the microhardness of the alloy. The highest microhardness of the alloy was achieved after aging at $800^{\circ} \mathrm{C}$.

\section{ACKNOWLEDGEMENTS}

This research was supported by Russian Science Foundation grant (project No 18-13-00111).

\section{REFERENCES}

[1] DAI, J., ZHU, J., CHEN, C. and WENG, F. High temperature oxidation behavior and research status of modifications on improving high temperature oxidation resistance of titanium alloys and titanium aluminides: $A$ review. Journal of Alloys and Compounds. 2016. vol. 685, pp. 784-798.

[2] CLEMENS, H. and MAYER, S. Intermetallic titanium aluminides in aerospace applications-processing, microstructure and properties. Materials at High Temperatures. 2016. vol. 33, no. 4-5, pp. 560-570.

[3] POLOZOV, I., SUFIIAROV, V. and SHAMSHURIN, A. Synthesis of titanium orthorhombic alloy using binder jetting additive manufacturing. Materials Letters. 2019. vol. 243, pp. 88-91.

[4] POLOZOV, I., SUFIIAROV, V., POPOVICH, A., MASAYLO, D. and GRIGORIEV, A. Synthesis of Ti-5AI, Ti-6AI$7 \mathrm{Nb}$, and Ti-22Al-25Nb alloys from elemental powders using powder-bed fusion additive manufacturing. Journal of Alloys and Compounds. 2018. vol. 763. pp. 436-445.

[5] WANG, Guofeng, JIANLEI, Yang and XIAO, Li. Microstructure and mechanical properties of a Ti- 22Al- 25Nb alloy fabricated from elemental powders by mechanical alloying and spark plasma sintering. Journal of Alloys and Compounds. 2017. vol. 704. pp. 425-433.

[6] WANG, Wei, et al. Microstructure control and mechanical properties from isothermal forging and heat treatment of Ti-22Al-25Nb (at\%) orthorhombic alloy. Intermetallics. 2015. vol. 56. pp. 79-86.

[7] JIA, Jianbo, et al. B2 grain growth behavior of a Ti-22AI-25Nb alloy fabricated by hot pressing sintering. Journal of Materials Engineering and Performance. 2018. vol. 27, no. 5, pp. 2288-2297. 